\title{
Lack of association of -607 C/A and -137 G/C polymorphisms in interleukin 18 gene with susceptibility to gout disease in Chinese Han male population
}

\author{
Changgui Li $\cdot$ Ying Yuan $\cdot$ Xinfeng Wang $\cdot$ \\ Lin Han $\cdot$ Nan Chu $\cdot$ Hui Wang $\cdot$ Shiguo Liu
}

Received: 22 December 2010 / Accepted: 13 March 2011 / Published online: 13 April 2011

(C) The Author(s) 2011. This article is published with open access at Springerlink.com

\begin{abstract}
To identify association of ILI8-607 C/A and -137 G/C polymorphism with susceptibility to gout in Chinese Han male population, We evaluate the genetic contribution of the IL18-607 C/A and -137 G/C polymorphism in 202 gout male patients and 493 gout-free control of Chinese Han population by allele-specific polymerase chain reaction assay. Our results reveal no significant association between the polymorphisms $-607 \mathrm{C} / \mathrm{A}$ and $-137 \mathrm{G} / \mathrm{C}$ in $I L 18$ with gout. Our study might suggest that $-607 \mathrm{C} / \mathrm{A}$ and $-137 \mathrm{G} / \mathrm{C}$ polymorphisms in the promoter of IL18 are not associated with susceptibility to gout and thus do not play a major role in the development of gout in the Chinese Han male population.
\end{abstract}

Keywords Gout $\cdot$ Polymorphisms - $-607 \mathrm{C} / \mathrm{A}$ and $-137 \mathrm{G} / \mathrm{C}$. Chinese Han male population

\section{Introduction}

Gout is often caused by deposition of monosodium urate crystals in the joint to induce acute attacks of arthritis inflammation, which develops into involvement of the joint deformity and dysfunction. Recently, with the improvement of social prosperity and the variation of diet structure, the prevalence and epidemiology of this disorder are more complex than was once thought, and have become the common inflammatory joint illness in men above 40 years of age especially in Chinese coast region. The epidemiological

C. Li and Y. Yuan have contributed equally to the work.

C. Li $\cdot$ Y. Yuan $\cdot$ X. Wang $\cdot$ L. Han $\cdot$ N. Chu $\cdot$ H. Wang $\cdot$ S. Liu $(\bowtie)$ Gout Laboratory, Medical School Hospital of Qingdao University, 16 Jiangsu Road, Qingdao 266003, China

e-mail: qdmc_genetics@163.com investigation of more than 5,000 residents from coast of Shandong province in 2004 indicated that the prevalence of gout was about $0.84 \%$, in men $1.94 \%$ and women $0.42 \%$ [1].

Previous research suggested that gout is in association with some of process such as activation of nuclear factor (NF)-kB and transcription production and secretion of ILlbeta and activation of the inflammasome [2]. As a member of the IL1 superfamily, ILI8, generated by activated mononuclear macrophage, is one of the widely distributed proinflammatory cytokines [3] and plays an important role in regulating the innate and adaptive immune systems [4]. Its two functional variants at positions -607 C/A (rs1946518) and $-137 \mathrm{G} / \mathrm{C}$ (rs187238) in the promoter region of the IL18 gene have important effect on its transcription activity [5].

To test the hypothesis that $-607 \mathrm{C} / \mathrm{A}$ and $-137 \mathrm{G} / \mathrm{C}$ polymorphisms in IL18 may influence disposition to gout development, the present study was conducted on the possible genetic association between this polymorphism and gout in a Chinese Han male population.

\section{Materials and methods}

Study population

A total of 202 gout male patients and 493 gout-free male controls were recruited in this study from Medical School Hospital of Qingdao University. The diagnosis of gout was based on the preliminary criteria, which were published by the American College of Rheumatology in 1997 for the classification of gout for use in either clinical settings or population-based epidemiologic studies. All subjects were provided written informed consent, and study protocol was approved by the Ethics Committee of Medical School Hospital of Qingdao University. 
DNA analysis and statistical analysis

Genomic DNA was extracted from whole blood samples using standard methods. Genotyping of each subject for the presence of $-607 \mathrm{C} / \mathrm{A}$ and $-137 \mathrm{G} / \mathrm{C}$ SNPs in the promoter of IL18 was performed using a previously described allelespecific polymerase chain reaction assay [6]. In addition, several subjects were selected to confirm genotype by DNA sequencing techniques. For all data of patients and controls, the Hardy-Weinberg equilibrium of the genotype distribution was tested using the homogeneity $\chi$ square test. A case-control study was performed using the homogeneity $\chi$ square test.

\section{Results}

A total of 202 gout patients and 493 gout-free controls participated in this study. The genotypic distribution was not significantly different from the distribution expected according to Hardy-Weinberg equilibrium in gout patients (for $-607 \mathrm{C} / \mathrm{A}, \chi^{2}=2.52$ with $1 d f$ and $P=0.112$; for $-137 \mathrm{G}$ / $\mathrm{C}, \chi^{2}=2.306$ with $1 d f$ and $P=0.115$ ) and control group (for -607 C/A, $\chi^{2}=2.478$ with $1 d f$ and $P=0.115$; for $-137 \mathrm{G} / \mathrm{C}$, $\chi^{2}=0.418$ with $1 d f$ and $P=0.517$ ). No significant differences were found in $-607 \mathrm{C} / \mathrm{A}$ and $-137 \mathrm{G} / \mathrm{C}$ genotypic and allelic frequencies between gout cases and controls (for -607 $\mathrm{C}>\mathrm{A}, \chi^{2}=0.320, d f=1, P=0.851$ by genotype; $\chi^{2}=0.071$, $d f=1, P=0.788$ by allele; for $-137 \mathrm{G} / \mathrm{C}, \chi^{2}=1.796, d f=1$, $P=0.407$ by genotype; $\chi^{2}=1.193, d f=1, P=0.274$ by allele).

\section{Discussion}

The previous studies indicated that $I L 18$ plays an important role in the immune regulation, anti-infection, and the pathogenic process of chronic inflammatory diseases, and ILI8 polymorphism in the promoter region has been noted associated with many kinds of diseases, such as type 1 diabetes [6], asthma [7], virus infective disease [8], rheumatoid arthritis [9] and so on. As two functional polymorphism position (-607 C/A and $-137 \mathrm{G} / \mathrm{C}$ ) in the promoter of $I L 18$, Low promoter activity was observed for the $\mathrm{A}$ and $\mathrm{C}$ alleles at positions -607 and -137 , respectively. In contrast, higher promoter activity was observed for the $\mathrm{C}$ and $\mathrm{G}$ alleles in these positions [5].

In the present study, we evaluate the genetic contribution of the IL18 -607 C/A and -137 G/C polymorphism in gout patients and 493 gout-free controls of Chinese Han population. Our results reveal no significant association between the polymorphisms $-607 \mathrm{C} / \mathrm{A}$ and $-137 \mathrm{G} / \mathrm{C}$ in $I L 18$ with gout. Although Inokuchi et.al detected the levels of IL18 in the plasma of 31 male patients with gouty arthritis and suggested that increased plasma levels of IL-18 reflect local inflammation associated with gouty arthritis [10], our result might suggest that IL18 promoter polymorphism is not associated with susceptibility to gout and thus does not play a major role in the development of gout in the Chinese Han male population. To our knowledge, this is the first report on investigating SNPs in ILI8 in relation to gout.

However, the present study has several limitations. First, we chose only 2 SNP locus and did not include enough polymorphic markers to cover the whole sequence of ILI8. So, the results of the present study should be interpreted with caution. Second, the power of the present study was limited by sample size. Last but not least, the lack of significance for $I L 18$ polymorphisms in conferring liability to gout disease does not exclude a role of different functional polymorphisms in genes coding for cytokine structures in the etiology of gout. Thus, further investigations with more polymorphic markers should be performed in a larger sample of Chinese Han male population and different population to validate our findings.

Acknowledgments We thank all probands for their participation. This work was supported by the National Basic Research Program of China (2010CB534902) and the National Natural Science Foundation of China (30570890 and 30871192).

Open Access This article is distributed under the terms of the Creative Commons Attribution Noncommercial License which permits any noncommercial use, distribution, and reproduction in any medium, provided the original author(s) and source are credited.

\section{References}

1. Miao Z, Li C, Chen Y, Zhao S, Wang Y, Wang Z et al (2008) Dietary and lifestyle changes associated with high prevalence of hyperuricemia and gout in the Shandong coastal cities of Eastern China. J Rheumatol 35:1859-1864

2. Torres R, Macdonald L, Croll SD, Reinhardt J, Dore A, Stevens S et al (2009) Hyperalgesia, synovitis and multiple biomarkers of inflammation are suppressed by interleukin 1 inhibition in a novel animal model of gouty arthritis. Ann Rheum Dis 68:1602-1608

3. Yuan BS, Zhu RM, Braddock M, Zhang XH, Shi W, Zheng MH (2007) Interleukin-18: a pro-inflammatory cytokine that plays an important role in acute pancreatitis. Expert Opin Ther Targets 11:1261-1271

4. Gracie JA, Robertson SE, McInnes IB (2003) Interleukin-18. J Leukoc Biol 73:213-224

5. Giedraitis V, He B, Huang WX, Hillert J (2001) Cloning and mutation analysis of the human IL-18 promoter: a possible role of polymorphisms in expression regulation. J Neuroimmunol 112: $146-152$

6. Kretowski A, Mironczuk K, Karpinska A, Bojaryn U, Kinalski M, Puchalski Z et al (2002) Interleukin-18 promoter polymorphisms in type 1 diabetes. Diabetes 51:3347-3349

7. Pawlik A, Kaminski M, Kusnierczyk P, Kurzawski M, Dziedziejko V, Adamska M et al (2007) Interleukin-18 promoter polymorphism in patients with atopic asthma. Tissue Antigens $70: 314-318$ 
8. Migita K, Sawakami-Kobayashi K, Maeda Y, Maeda Y, Nakao K, Kondoh $\mathrm{S}$ et al (2009) Interleukin-18 promoter polymorphisms and the disease progression of Hepatitis B virus-related liver disease. Transl Res 153:91-96

9. Gracie JA, Koyama N, Murdoch J, Field M, McGarry F, Crilly A et al (2005) Disease association of two distinct interleukin-18 promoter polymorphisms in Caucasian rheumatoid arthritis patients. Genes Immun 6:211-216

10. Inokuchi T, Moriwaki Y, Tsutsui H, Yamamoto A, Takahashi S, Tsutsumi $\mathrm{Z}$ et al (2006) Plasma interleukin (IL)-18 (interferongamma-inducing factor) and other inflammatory cytokines in patients with gouty arthritis and monosodium urate monohydrate crystal-induced secretion of IL-18. Cytokine 33:21-27 